\title{
CHALLENGES FOR R\&D AND INNOVATION IN ENERGY
}

Costa-Campi, M.T., Department of Public Economics, Chair of Energy Sustainability and Barcelona Institute of Economics (IEB), University of Barcelona. E-mail: mtcosta@ub.edu

García-Quevedo, J., Department of Public Economics, Chair of Energy Sustainability and Barcelona Institute of Economics (IEB), University of Barcelona. E-mail: jgarciaq@ub.edu

Trujillo-Baute, E., Chair of Energy Sustainability and University of Warwick. E-mail: elisatrujillo@ub.edu

\begin{abstract}
In recent years, there has been a growing interest in the role of $R \& D$ and innovation in energy efficiency and dealing with climate change. To improve our knowledge of these matters a workshop was organised in Barcelona, Spain, in January 2014. This introduction to the special issue first presents some insights from the literature on challenges for $R \& D$ and innovation in energy. The second section summarises the articles from this workshop that make up this special issue and that provide new insights into innovation in energy. All the articles include energy policy recommendations based on the empirical analyses carried out.
\end{abstract}

Keywords: energy innovation, climatic change, R\&D, energy efficiency 
1. Introduction: Challenges for $\mathrm{R} \& \mathrm{D}$ and innovation in energy

The important role that innovation has in improving energy efficiency, competitiveness and facing the challenges posed by climatic change has led to an increasing interest in knowledge about innovation and R\&D activities in the energy sector and in the proper public policies to promote these activities (Alic et al., 2010; Anadon et al., 2011; OECD, 2011; Economics for Energy, 2013; Costa-Campi et al., 2014, Jamasb and Pollit, 2015). Although there is a consensus on the economic and environmental benefits of developing new energy technologies and that innovation is a key factor in achieving energy objectives related with efficiency, environmental impact and security of supply, our knowledge on how to foster them remains insufficient.

Most empirical analyses of $R \& D$ and innovation in energy firms have focused on the effects of the liberalisation process on $R \& D$ and innovation projects and activities (Markard and Truffer, 2006; Jamasb and Pollit, 2008; Sanyal and Cohen, 2009; Salies, 2010; Kim et al., 2012; Sterlacchini, 2012; Sanyal and Ghosh, 2013). More recently, some empirical analyses have examined the R\&D determinants and the obstacles to innovation after liberalisation (Salies, 2010; Sterlacchini, 2012; Sanyal and Ghosh, 2013; Costa-Campi et al., 2014). In addition, public policies and institutional framework characteristics have received considerable attention in the analysis of the energy innovation system (see, among others, Gallagher et al., 2012).

The energy industry, despite its importance in the economy, has traditionally shown a low level of expenditure on R\&D (GEA, 2012). Moreover with the liberalisation process, which began in the early 1990s, there was a decrease in R\&D investments, both in the United States and in the majority of European countries, although recently a small recovery seems to have occurred (Jamasb and Pollit, 2015). The liberalisation process has brought with it profound changes in the energy industry that have affected the R\&D investment decisions of firms that, in this new competitive situation, follow criteria that are different to those of the period before reform. In this framework energy firms adopt new competitive strategies focused on the one hand on efficiency in processes to reduce costs and increase margins, and on the other on differentiation in contracts, given that energy is a homogenous product (Jamasb and Pollit, 2008). 
Under competitive market conditions utilities should reduce costs and adapt to demand. The $R \& D$ projects that take a long time to mature are displaced by those with rapid implementation and returns. In addition, the low growth rate of demand for electricity in OECD countries also forces utilities to give up long-term projects (Jamasb and Pollit, 2008; Salies, 2010). In a context in which the new regulatory framework does not allow the recovery of the total cost of long-term $R \& D$ projects, firms change their objectives and reduce the volume of investment (Sterlacchini, 2012).

Technology and innovation in the energy sector present some specific characteristics in comparison to other sectors in the economy. Market failures related with R\&D activities are more intense in the energy sector. Indivisibility, spillovers and uncertainty affect energy R\&D in a significant way (Jamasb and Pollit, 2008). Similarly, the close relationship with the environment explains why investments in $R \& D$ in the energy sector produce greater positive externalities than other activities. The existence of spillovers creates problems of appropriability and reduces private incentives for investment (Salies, 2010; Kim et al., 2012).

In addition, innovation in the energy industry may be driven by some specific forces and face specific barriers related to the characteristics of the innovation activities in this industry. Some of the characteristics that may affect the innovative behaviour of the firms and the low level of $R \& D$ investment in this sector are the large scale of the $R \& D$ projects, the dominance of existing technologies, preference for incremental innovations or the greater size of the firms in this sector that may allow them to overcome financial barriers more easily than firms in other sectors.

The energy industry currently presents, after the liberalisation process, a set of characteristics that affect its investments in $R \& D$. First, the process of total or partial privatisation has meant the practical disappearance of the old public monopolies. Second, size is a barrier to entry in deciding to invest in R\&D (Salies, 2010; Kim et al., 2012; Sanyal and Cohen, 2012, Costa-Campi et al., 2014). Third, a small number of analyses have also considered the barriers to $\mathrm{R}+\mathrm{D}$ of cost and financing. The empirical results suggest that firms do not have financial restrictions as the availability of liquidity does not affect their R\&D investment decisions (Salies, 2010; Sanyal and Cohen, 2012). More recent analyses (Costa-Campi et al., 2014) have included the study of other 
barriers related to access to knowledge and the market structure. Their results coincide in that financial barriers are not a determinant in explaining $R \& D$ investments, but on the other hand market domination by established firms has a significant negative influence on innovation in the sector. These results suggest that the technological mix of energy generation affects $\mathrm{R}+\mathrm{D}$ and innovation, as is stated in other analyses. (Markard and Truffer, 2006; Anadon and Holdren, 2009; Salies, 2010; Anadon, 2012; Sterlacchini, 2012).

Generally the literature maintains that business investment in $R \& D$ and innovation is approached with objectives and returns in the short term. The improvement of energy efficiency in the industry and innovation in the technology of generation and the application of digitalization to networks and metering in the energy sector are clearly objectives of this type. In recent research it can also be observed that firms are fostering innovation to reduce their environmental impact. These investment decisions allow a positive relation to be established between a smart regulation to encourage responsible environmental practices and self-regulation. The firms incorporate these environmental innovations as a new competitive strategy based on differentiation and reputation compared to competitors and with a view to attracting smart investors. These investments all represent incremental innovations the effectiveness of which is measured by improved profits.

This new focus on competition allows private and public objectives and performance to be joined. Smart regulation and self-regulation explain the recovery of investments in $R \& D$ in the energy sector, but their incremental and applied nature do not allow them alone to tackle the great challenges of energy policy. The mitigation of climate change is a commitment that demands a broader approach with a longer view. A large amount of resources, and the involvement of the scientific community, of governments and private agents are necessary to achieve these objectives. The research projects are longterm and their returns are of social and economic interest for society as a whole. These investments in $R \& D$ have sunk costs and their application usually has a long precompetitive period. These characteristics justify public-private collaboration. (Newell, 2010; Henderson and Newell, 2011). 
These investments in $R \& D$ are of a systemic and disruptive nature, for which reason it is not the firms that will take on these projects. A forward-looking climate change policy demands support for $\mathrm{R}+\mathrm{D}$ through subsidies to research by firms and public investment in projects with specific objectives that involve energy firms, suppliers and consumers. (Anadon and Holdren, 2009). The literature underlines the pull effect of public investment on private investment in all segments of the industrial process of utilities and suppliers (Gallagher at al., 2012), a matter of special importance in the energy sector given that a large part of the $R \& D$ and innovation takes place in the firms that supply the technology. The experiences studied in the literature are not conclusive with regard to the design of the institutional framework in which a public-private energy policy should be developed, even though the creation of independent institutions composed of scientists and business people and supported by public capital appears to obtain favourable results in the United States, and with a different format, in the United Kingdom and China. Nevertheless, these experiences have not yet been functioning for a period long enough to provide solid information and results (Anadon, 2012).

The climate change mitigation objective is the cornerstone of European energy policy. The documents on climate and energy for the period 2020-2030 (European Commission, 2014 and 2015) situate R\&D as one of the five mutually-reinforcing and closely interrelated dimensions designed to bring greater energy security, sustainability and competitiveness. However, to this date there is no institutional design available for a vehicle for this new focus of the European Commission.

To sum up, recent studies of $R \& D$ and innovation in the energy sector have allowed advances to be made in knowledge about the effects of liberalisation, about some characteristics of firms that influence their $R \& D$ investment decisions in a market situation and about public policies to foster innovation in energy. Nevertheless, new analyses are necessary to have more precise knowledge of $R \& D$ activities in the sector and their strategies and effects and to design suitable policies to foster R\&D and innovation in the sector.

In order to advance knowledge regarding the role of R\&D and energy technologies and the public policies to foster them, a workshop was organised in Barcelona in January 2014, where the papers of this special issue were presented. In this introduction, we 
have first examined some of the challenges to R\&D and innovation in energy. In the next section, we introduce the articles that make up this special issue.

2. Overview of the contributions to the special issue

The papers in this special issue deal with $R \& D$ and innovation in energy. In the first paper, Jamasb and Pollit (2015) present an overview of the effects of electricity market liberalisation on innovation. In particular, they revise and update their previous findings on the effects of privatisation, market based reforms and incentives on R\&D and patenting activities in the electricity sector in the UK. Their results show that energy $\mathrm{R} \& \mathrm{D}$ expenditure declined after liberalisation but that it has also partially recovered. They also pointed out that profit incentives have shifted $R \& D$ resources to near market innovation and that $R \& D$ productivity measured by the ratio between patents and $R \& D$ expenditure has increased. From their analysis they suggest a number of implications for energy R\&D policies. First, they emphasize that the main role of government support should be oriented towards basic research and to encouraging collaborative research. Second, that a key factor in innovation policies is long-term stability and regulatory commitment. Third, they stress that energy $R \& D$ needs to pay attention to "social technology". Finally, they underline the importance of the division of the R\&D roles for the different public and private actors involved in electricity technology and innovation.

The next two papers deal with the sources of knowledge for energy technologies (Rexhäuser and Löschel, 2015) and the location of green R\&D activities (Noailly and Ryfisch, 2015) respectively. Rexhäuser and Löschel (2015) examine, first, the role that prior inventions in renewable energy and in energy efficiency or conservation have, as a technology push factor, on both technologies. In addition, they also study the effect of previous inventions in non-energy technologies on energy technologies. This analysis helps to improve our understanding of the different sources of knowledge for energy inventions. The empirical analyses carried out at a firm level with panel data show that the results differ significantly. First, for both energy technologies there is path dependency but it is stronger for renewable energy technologies than for energy conservation inventions. Second, non-energy technologies are only significant and positively related to energy efficiency inventions. From these results, they emphasize 
the role that suppliers have in energy efficiency inventions and the positive effects that general policies to promote innovation may have on energy conservation technologies.

Noailly and Ryfisch (2015) analyse the geographic location of green R\&D. Specifically, they examine, using data on patents, the internationalisation of green technologies by multinational firms. After showing the importance of this phenomenon, finding that about $17 \%$ of green patents are a result of multinational $R \& D$ investments conducted outside their home countries, they carry out an empirical analysis to examine their determinants. The results show that together with the factors that explain the globalisation of R\&D activities, such as market size, the R\&D intensity of the host country or IPR, local environmental regulation and specific technological abilities in green technologies are important drivers of multinational green $R \& D$ location decisions. In particular, local environmental policies are an incentive for the creation of local demand for green technologies and have a positive effect on encouraging local firms to engage in green innovation, increasing their absorptive capacity. These results show the importance of combining, as emphasized by current literature, environmental and technology policy instruments to attract $\mathrm{R} \& \mathrm{D}$ investments and to promote the development of green technologies.

The following three papers focus on the effects of innovation on energy efficiency and on the international distribution of energy intensities. In the first of these three papers, Costa-Campi et al. (2015) examine the extent to which innovative Spanish firms pursue improvements in energy efficiency as an objective of innovation. Their results underline the role of size among the characteristics of firms that facilitate energy efficiency innovation. The variables relating to the firm's behaviour also show that investment in tangible assets has a direct relationship with a commitment to energy efficiency, while investments in R\&D do not affect the firm's capacity to improve its energy efficiency. Additionally, the econometric estimations show that environmental and energy efficiency objectives complement each other and highlight the importance of organizational innovations as a key factor related to energy efficiency improvements. From these results, the authors emphasize the need to design cross-cutting policies that generate incentives for innovative firms to jointly tackle the challenges associated with energy efficiency and environmental sustainability without compromising their competitiveness. 
Cagno et al. (2015) also analyse the link between innovation practices and energy efficiency but for a specific industry, the foundry sector, in Italy. Through a selfreported questionnaire they examine the relationships between six different indicators of the firms' level of innovativeness and three measures of energy efficiency. The results show a positive relationship between innovation and energy efficiency and that the firms that complement internal $R \& D$ with inbound open innovation practices have a higher level of energy efficiency and a lower perception of barriers to efficiency improvements. Their results offer information about innovation practice and energy management that may help to identify innovation policy initiatives to improve energy efficiency.

Duro (2015) carried out an appraisal of international energy efficiency and sustainability in the consumption of resources. Through an empirical evaluation of the distribution of energy intensities by means of descriptive tools from the analysis of inequality and polarization, the focus is concerned with inequalities and their explanatory factors, along with the polarization of intensities between groups of countries that are endogenously and exogenously defined. The results obtained suggest that the reduction of energy intensity levels has coincided with a reduction in crosscountry inequalities, the cross-country energy intensity inequalities depending on regional groups. In spite of the reduction in world mean intensities and their inequality across countries, energy consumption in per capita terms has increased rapidly. The big challenge in environmental and energy policy is the absolute decoupling of energy and economic growth, which would be a key element in a sustainable development strategy. It would be necessary to intensify energy-saving technologies, improve the use of energy resources and encourage activities that do not use energy intensively on a worldwide scale.

The next paper analyses the diffusion of energy technologies, specifically oil and gas technologies, with environmental uses. Costa-Campi and Duch-Brown (2015) claim in their paper that the adequate diffusion of existing technologies could introduce significant improvements in the alleviation of environmental impacts. In particular, they look at the oil and gas industry and assess the diffusion of knowledge linked to environmental technologies developed within that sector. The proposed measure of 
knowledge spillovers is based on forward patent citations. The authors conclude that knowledge spillovers in the oil and gas industry are rather low, which in turns suggests that there is no need for specific policy instruments designed to address technology policies in this sector. On the contrary, they argue, environmental policies would have a larger impact by stimulating the development of green technologies. A major drawback identified by the authors comes from the fact that environmental policies are designed and implemented at a national level while the degree of international cooperation is low. In sum, both a switch to more effective environmental policies and global action would be needed to achieve significant improvements in the protection of the environment by the oil and gas industry.

Finally, the last two papers examine the effects of policy measures - environmental regulations- on innovation and competitiveness. Regarding the link between environmental regulation and innovation, in a sample of 25 European countries, Kounetas (2015) estimated countries' technical (TGs) and environmental efficiency (EETGs) with regard to the relevant technology gaps during two different critical periods of the implementation of Kyoto using different frontier configurations. The overall results indicate the crucial role of heterogeneous technologies in technology gaps in both periods. According to the empirical results, it is evident that technology gaps in European countries saw, on average, a significant decrease during the two periods under examination. The results obtained with respect to the EETGs suggest that a significant improvement of the meta-technology ratio exists in the European context. Moreover, a significant decrease for both measures, although with different percentages, was recorded, emphasizing the key role of knowledge spillovers. The fact that significant technological gaps exist introduces the concept of investing in technology in order that lagging countries can catch up with leader countries. International coordination and cooperation in the development of infrastructures, technologies and techniques, the elimination of knowledge gaps, the presentation and diffusion of best practice policies, the creation of common strategies and objectives particularly concerning the environment will help individual countries to tackle specific environmental threats per se and minimize their effects.

Rubashkina et al., (2015) analyse the nexus between environmental regulation and competitiveness through the investigation of the hypothesis that well-crafted and well- 
enforced regulation would benefit both the environment and the firm, i.e. the Porter Hypothesis $(\mathrm{PH})$. Using information on the manufacturing sectors of 17 European countries, they look at the overall innovation and productivity impact of environmental regulation, with pollution abatement and control expenditure (PACE) as a proxy for environmental policy stringency. The empirical study is developed for both the overall innovative activity proxied by patents, and the productivity impacts as the indicators of the "strong" PH. Evidence was found of a positive impact of environmental regulation on the output of innovation activity, thus providing support in favour of the "weak" PH. This evidence has important policy implications. Increased environmental regulation did not result in lower innovation levels, hence, sectors somehow adapt to tighter regulation, by either shifting inputs or increasing productivity, in such a way that it does not impair the output of their innovative activity. No evidence was found in favour of the "strong" $\mathrm{PH}$, as productivity appears to be unaffected by the degree of pollution control and abatement efforts. From a policy perspective, this should somehow ease concerns that European manufacturing sectors could be penalized because of increased domestic environmental policy stringency. 
Acknowledgements

The editors would like to thank all those involved in the "International Academic Symposium R\&D on Energy" held on 28 January, 2014, in Barcelona, Spain. Special thanks are given to the event Keynotes Michael Pollitt (Cambridge Judge Business School) and Jean-Michel Glachant (European University Institute), and to the ChairDiscussants Paulina Beato (Economic Adviser), Xavier Labandeira (Universidad de Vigo), and Pedro Linares (Universidad Pontificia Comillas). All the papers in this special issue were sent for a blind peer review process, with at least two referees. The contribution of the referees with their valuable comments and suggestions, improved these special issue papers. Thanks to all of them. We would also like to thank the Energy Policy editor Dr. Lorna Greening and Carrie Palmer for their support during the review, production and publication processes. We are also grateful for the generous support of the Chair of Energy Sustainability (Barcelona Institute of Economics, University of Barcelona), the Generalitat de Catalunya SGR project 2014-SGR-531, and the sponsorship by the FUNSEAM (Energy and Environmental Sustainability Foundation). The authors are solely responsible for the views expressed here, as well as all errors and omissions. 
Alic, J.; Sarewitz, D.; Weiss, Ch.; Bonvillian; W. 2010. A new strategy for energy innovation, Nature 466, 316-317.

Anadon, L., Holdren, J. 2009. Policy for Energy Technology Innovation, in Gallagher, K. (Ed.) Acting in Time on Energy Policy. Chap. 5, Washington, D.C.: Brookings Institution Press

Anadon, L., Bunn, M., Chan, G., Chan, M., Jones, C., Kempener, R., Lee, A., Logar, N., Narayanamurti, V., 2011. Transforming U.S. energy innovation. Energy Technology Innovation Policy research group. Belfer Center for Social and International Affairs, Harvard Kennedy School, Cambridge, MA.

Anadon, L., 2012. Missions-oriented RD\&D institutions in energy between 2000 and 2010: A comparative analysis of China, the United Kingdom, and the United States, Research Policy 41, 1742-1756.

Cagno, E., Ramirez-Portilla, A., Trianni, A. 2015. Linking energy efficiency and innovation practices: Empirical evidence from the foundry sector. Energy Policy, doi:10.1016/j.enpol.2015.02.023

Costa-Campi, M. T.; Duch-Brown; N.; García-Quevedo, J. 2014, R\&D drivers and obstacles to innovation in the energy industry. Energy Economics 46, 20-30.

Costa-Campi, M. T.; Duch-Brown; N. 2015. The diffusion of patented oil and gas technology with environmental uses: A forward patent citation analysis. Energy Policy, doi: 10.1016/j.enpol.2015.03.001.

Costa-Campi, M.T., García-Quevedo, J.; Segarra, A. 2015. Energy efficiency determinants: An empirical analysis of Spanish innovative firms. Energy Policy, doi: 10.1016/j.enpol.2015.01.037.

Duro, J.A., 2015. The international distribution of energy intensities. Energy Policy, doi:

Economics for Energy, 2013. Innovación en energía en España. Análisis y recomendaciones. Informe 2012. Economics for Energy, Vigo, Spain.

European Commission, 2014. A policy framework for climate and energy in the period from 2020 to 2030. COM(2014) 15 final.

European Commission, 2015. Energy Union Package.A Framework Strategy for a Resilient Energy Union with a Forward-Looking Climate Change Policy Brussels, 25.2.2015 $\operatorname{COM}(2015) 80$ final.

Gallagher, K., Grübler, A., Kuhl, L. Nemet, G., Wilson, Ch., 2012. The energy technology innovation system. Annual Review of Environmental Resources 37, 137162.

GEA, 2012. Global Energy Assessment. Towards a sustainable future, Cambridge University Press, Cambridge, UK and New York, USA.

Henderson, R. M., Newell, R. G., 2011. Accelerating Energy Innovation: Insights from Multiple Sectors. University of Chicago Press.

IEA 2012. World Energy Outlook. International Energy Agency, OECD.

Jamasb, T., Pollitt, M., 2008. Liberalisation and R\&D in network industries: The case of the electricity industry. Research Policy 37, 995-1008.

Jamasb, T., Pollitt, M., 2015. Why and how to subsidise energy R\&D: Lessons from the collapse and recovery of energy innovation in the UK. Energy Policy, doi: 10.1016/j.enpol.2015.01.041.

Kim, J., Kim, Y., Flacher, D., 2012. R\&D investment of electricity-generating firms following industry restructuring. Energy Policy 48, 103-117. 
Kounetas, K. 2015. Heterogeneous technologies, strategic groups and environmental efficiency technology gaps for European countries. Energy Policy, doi: 10.1016/j.enpol.2015.01.036.

Markard, J., Truffer, B., 2006. Innovation processes in large technical systems: Market liberalization as a driver for radical change? Research Policy 35, 609-625.

Newell, R. G., 2010. The role of markets and policies in delivering innovation for climate change mitigation. Oxford Review of Economic Policy 26, 253-269.

Noailly, J., Ryfisch, D. 2015. Multinational firms and the internationalization of green R\&D: A review of the evidence and policy implications, Energy Policy, doi:10.1016/j.enpol.2015.03.002

OECD, 2011. Fostering innovation for green growth. Organisation for Economic Cooperation and Development, Paris.

Rexhüaser, S., Löschel, A. 2015. Invention in energy technologies: Comparing energy efficiency and renewable energy inventions at the firm level. Energy Policy, doi:10.1016/j.enpol.2015.02.003.

Rubashkina, Y., Galeotti, M., Verdolini, E. 2015. Environmental regulation and competitiveness: Empirical evidence on the Porter Hypothesis from European manufacturing sectors. Energy Policy, doi:10.1016/j.enpol.2015.02.014.

Salies, E., 2010. A test of the Schumpeterian hypothesis in a panel of European Electric Utilities, in: J.L Gaffard, J.L., Salies, E., Innovation, Economic Growth and the Firm. Edward Elgar Publishing.

Sanyal, P., 2007. The effect of deregulation on environmental research by electric utilities. Journal of Regulatory Economics 31, 335-353.

Sanyal, P., Cohen, L. R., 2009. Powering Progress: Restructuring, Competition, and R\&D in the U.S. Electric Utility Industry. The Energy Journal 30, 41-79.

Sanyal, P., Ghosh, S., 2013. Product Market Competition and Upstream Innovation: Evidence from the U.S. Electricity Market Deregulation. Review of Economics and Statistics 95, 237-254.

Sterlacchini, A., 2012. Energy R\&D in private and state-owned utilities: An analysis of the major world electric companies. Energy Policy 41, 494-506. 